Research Paper

\title{
mTOR signaling mediates resistance to tankyrase inhibitors in Wnt-driven colorectal cancer
}

\author{
Tetsuo Mashima ${ }^{1}$, Yoko Taneda ${ }^{1,2}$, Myung-Kyu Jang ${ }^{1,2}$, Anna Mizutani ${ }^{1}$, Yukiko \\ Muramatsu ${ }^{1}$, Haruka Yoshida ${ }^{1}$, Ayana Sato ${ }^{1,2}$, Noritaka Tanaka ${ }^{1,3}$, Yoshikazu \\ Sugimoto $^{3}$ and Hiroyuki Seimiya ${ }^{1,2}$

\footnotetext{
${ }^{1}$ Division of Molecular Biotherapy, Cancer Chemotherapy Center, Japanese Foundation for Cancer Research, Tokyo, Japan

${ }^{2}$ Department of Computational Biology and Medical Sciences, Graduate School of Frontier Sciences, The University of Tokyo, Tokyo, Japan

${ }^{3}$ Division of Chemotherapy, Faculty of Pharmacy, Keio University, Tokyo, Japan
}

Correspondence to: Hiroyuki Seimiya, email: hseimiya@jfcr.or.jp

Keywords: tankyrase, Wnt, colorectal cancer, resistance, mTOR

Received: August 26, $2016 \quad$ Accepted: May 03, $2017 \quad$ Published: May 24, 2017

Copyright: Mashima et al. This is an open-access article distributed under the terms of the Creative Commons Attribution License 3.0 (CC BY 3.0), which permits unrestricted use, distribution, and reproduction in any medium, provided the original author and source are credited.

\section{ABSTRACT}

Activation of Wnt/ $\beta$-catenin signaling is essential for colorectal carcinogenesis. Tankyrase, a member of the poly(ADP-ribose) polymerase (PARP) family, is a positive regulator of the $\mathrm{Wnt} / \boldsymbol{\beta}$-catenin signaling. Accordingly, tankyrase inhibitors are under preclinical development for colorectal cancer (CRC) therapy. However, Wnt-driven colorectal cancer cells are not equally sensitive to tankyrase inhibitors, and cellular factors that affect tankyrase inhibitor sensitivity remain elusive. Here, we established a tankyrase inhibitor-resistant cell line, 320-IWR, from Wnt/ $\beta$ catenin-dependent CRC COLO-320DM cells. 320-IWR cells exhibited resistance to tankyrase inhibitors, IWR-1 and G007-LK, but remained sensitive to a PARP-1/2 inhibitor, olaparib, and several anti-CRC agents. In 320-IWR cells, nuclear localization of active $\beta$-catenin was decreased and expression of $\beta$-catenin target genes was constitutively repressed, suggesting that these cells repressed the $W n t / \beta$-catenin signaling and were dependent on alternative proliferation pathways. 320-IWR cells exhibited upregulated $m$ TOR signaling and were more sensitive to $m$ TOR inhibition than the parental cells. Importantly, mTOR inhibition reversed resistance to tankyrase inhibitors and potentiated their anti-proliferative effects in 320-IWR cells as well as in CRC cell lines in which the mTOR pathway was intrinsically activated. These results indicate that mTOR signaling confers resistance to tankyrase inhibitors in CRC cells and suggest that the combination of tankyrase and $\mathrm{mTOR}$ inhibitors would be a useful therapeutic approach for a subset of CRCs.

\section{INTRODUCTION}

Colorectal cancer (CRC) is a leading cause of cancer death worldwide. In the treatment of metastatic CRC, conventional chemotherapy and several molecularlytargeted drugs are currently used as standard drugs [1]. However, the effectiveness of these drugs is limited, and development of additional new drugs is required to improve treatment outcome. In CRC, multi-step genetic changes drive tumor development [2]. Together with mutations in oncogenes and tumor suppressor genes, such as $K R A S, p 53$, and $S M A D 4$, activation of the canonical $\mathrm{Wnt} / \beta$-catenin signaling pathway is a critical event in colorectal tumorigenesis. The $\mathrm{Wnt} / \beta$-catenin signaling activation is mainly caused by loss-of-function mutations in the adenomatous polyposis coli $(A P C)$ gene [3]. In most sporadic CRC cases, mutations in $A P C$ occur, which lead to stabilization of $\beta$-catenin and activation of 
downstream TCF/LEF-mediated transcription $[3,4]$. The $\mathrm{Wnt} / \beta$-catenin pathway plays an essential role not only in CRC initiation but also in tumor maintenance [5]. These observations indicate that $\mathrm{Wnt} / \beta$-catenin signaling is a rational therapeutic target for CRC.

Tankyrase is a member of the poly(ADP-ribose) polymerase (PARP) family of proteins, originally identified as a telomeric repeat binding factor-interacting protein [6]. Tankyrase recognizes its substrate proteins through the multiple ankyrin repeat cluster domains for PARylation and is involved in telomere homeostasis and in other biological events such as mitosis $[6,7]$. Since the discovery of tankyrase as a positive regulator of $\mathrm{Wnt} / \beta$ catenin signaling [8], tankyrase has particularly been considered as a promising molecular target for CRC therapy and studies on tankyrase inhibitor development is actively ongoing. In Wnt/ $\beta$-catenin pathway, tankyrase PARylates Axin, a negative regulator of the Wnt pathway, leading to its ubiquitylation by RNF146 and proteasomemediated degradation [9]. As a result, tankyrase causes $\beta$-catenin stabilization and positively regulates the $\mathrm{Wnt} / \beta$ catenin signaling pathway. Recently, several tankyrase inhibitors have been developed, including XAV939, IWR-1, G007-LK and AZ1366 [10-13]. In CRC cells, tankyrase inhibitor treatment particularly accumulates Axin2 protein level and causes $\beta$-catenin degradation. Among the tankyrase inhibitors reported, G007-LK and AZ1366 were shown to effectively suppress CRC growth in vivo, utilizing CRC cell lines and patient-derived tumor xenograft, respectively $[12,13]$.

However, recent reports have shown that not all Wnt/ $\beta$-catenin-driven CRC cells are sensitive to tankyrase inhibitors $[12,13]$. So far, little information is available as to what determines cellular sensitivity to tankyrase inhibitors. To establish successful tankyrase-targeting therapy for CRC treatment, it is critical to identify the cellular factors that affect sensitivity to the agents and further develop predictive biomarkers for the selection of patient groups to undergo therapy.

To understand the molecular pathways that affect cellular sensitivity to tankyrase inhibitors, we established a novel tankyrase inhibitor-resistant cell line, 320-IWR, from Wnt/ $\beta$-catenin-dependent CRC COLO-320DM cells. Through the analysis of these resistant cells, we identified the mTOR pathway, an important proliferation factor in various cancers including $\mathrm{CRC}$, as a crucial resistant factor to tankyrase inhibitors.

\section{RESULTS}

\section{Tankyrase inhibitors suppress CRC COLO- 320DM cell proliferation through $\beta$-catenin degradation}

Among the $A P C$-mutated CRC cell lines, COLO320DM cells are sensitive to tankyrase inhibitors [12].
To clarify the significance of $\beta$-catenin downregulation after drug treatment in the suppression of COLO-320DM cell proliferation, we overexpressed constitutively active $\beta$-catenin with a deleted mutation at $\operatorname{Ser} 45[\beta-\operatorname{cat}(\mathrm{S} 45 \Delta)$ FLAG] in the cells. This $\beta$-catenin mutant is not phosphorylated by casein kinase I $\alpha(\mathrm{CK} 1 \alpha)$ at Ser45 and is thereby resistant to subsequent phosphorylation at Ser41, Ser37 and Ser33 by glycogen synthase kinase $3 \beta$ (GSK-3 $\beta$ ), which is required for proteasomemediated degradation $[14,15]$. It was also shown that the $\beta$-cat(S45 $\Delta$ ) stimulates TCF reporter activity much stronger than the wild-type $\beta$-catenin even without Wnt ligand [16]. As expected, when COLO-320DM cells were treated with IWR-1, a tankyrase inhibitor, Axin2 protein accumulated and endogenous active $\beta$-catenin protein levels were reduced (Figure 1A). In contrast, $\beta$-cat(S45 $\Delta$ )FLAG was resistant to degradation even upon the tankyrase inhibitor treatment and active $\beta$-catenin levels were maintained after inhibitor treatment (Figure 1A). Importantly, growth inhibition by IWR-1 and another tankyrase inhibitor G007-LK was strongly prevented in these $\beta$-catenin mutant-expressing cells (Figure 1B). These results indicate that down-regulation of active $\beta$-catenin is a critical step in the growth inhibition of COLO-320DM cells treated with tankyrase inhibitors.

\section{Establishment of tankyrase inhibitor-resistant 320-IWR cells}

To understand the mechanism of resistance to tankyrase inhibitors in CRC cells, we established tankyrase inhibitor-resistant cells from COLO-320DM cells. IWR-1 at the concentration of $3 \mu \mathrm{M}$ induced Axin2 accumulation and subsequent down-regulation of active $\beta$-catenin, leading to cell growth inhibition (Figure 1A and 2A). Hence, we continuously treated COLO-320DM cells with IWR-1 at this concentration for 173 days and successfully established a tankyrase inhibitor-resistant cell line, designated as 320-IWR. The morphology of 320-IWR cells was similar to that of the parental COLO-320DM cells (Supplementary Figure 1A). The proliferation rate of 320-IWR cells was almost comparable to that of the parental cells although the resistant cells grew slightly slower (Supplementary Figure 1B): the doubling times of COLO320-DM and 320-IWR cells were $20 \mathrm{~h}$ and $22 \mathrm{~h}$, respectively.

320-IWR cells showed marked resistance to IWR-1 (Figure 2A, left). The $\mathrm{GI}_{50}$ values of IWR-1 in COLO$320 \mathrm{DM}$ and 320-IWR cells were $0.87 \mu \mathrm{M}$ and $>9 \mu \mathrm{M}$, respectively, indicating that 320 -IWR cells were more than 10.3-fold resistant to IWR-1. 320-IWR cells also showed cross-resistance to G007-LK, another tankyrase inhibitor with a different chemical structure to IWR1 (Figure 2A, right). The $\mathrm{GI}_{50}$ values of G007-LK in COLO320DM and 320-IWR cells were $0.71 \mu \mathrm{M}$ and $7.0 \mu \mathrm{M}$, respectively, indicating that $320-\mathrm{IWR}$ cells 
were 9.9-fold resistant to G007-LK. Flow cytometry analysis revealed that tankyrase inhibitors suppressed COLO-320DM cell growth without significant apoptosis induction (as revealed by sub-G1 fraction) or arrest at specific phase of the cell cycle (Supplementary Figure $2 \mathrm{~A}$ and Supplementary Table 1). In addition, there was no marked difference in cell cycle distribution between COLO-320DM and 320-IWR cells, though slight decrease of G1 and S phase and increase of G2/M phase cells were observed in 320-IWR cells. To examine whether the tankyrase inhibitor-resistant phenotype was stable, we cultured 320-IWR cells for 36 days in the absence of IWR-1. After the drug-free culture, 320-IWR cells maintained resistance to IWR-1 and G007-LK (Supplementary Figure 2B). To confirm that 320-IWR cells were resistant to tankyrase inhibition, we further knocked down the two tankyrase isozymes, tankyrase-1 and -2, simultaneously. We found that 320IWR cells were highly resistant to tankyrase knockdown (Supplementary Figure 3).
320-IWR cells did not show cross-resistance to olaparib, a PARP1/2 inhibitor, but rather showed collateral sensitivity to the agent (Figure 2B). 320-IWR cells did not show resistance to therapeutic drugs for $\mathrm{CRC}$, including regorafenib, 5-fluorourail (5-FU) or SN38, the active metabolite of irinotecan (Figure 2B). These observations indicate that 320 -IWR is a stable cell line, showing selective resistance to tankyrase inhibitors.

\section{Alteration of canonical Wnt/ß-catenin signaling in 320-IWR cells}

COLO-320DM and 320-IWR cells expressed comparable levels of tankyrase (Figure 2C). Because tankyrase PARylates itself for proteasome-dependent degradation, tankyrase inhibition leads to accumulation of tankyrase itself [12]. IWR-1 and G007-LK induced accumulation of tankyrase in 320-IWR cells in a similar manner to the parental cells (Figure 2C). These results indicate that both inhibitors were incorporated into the
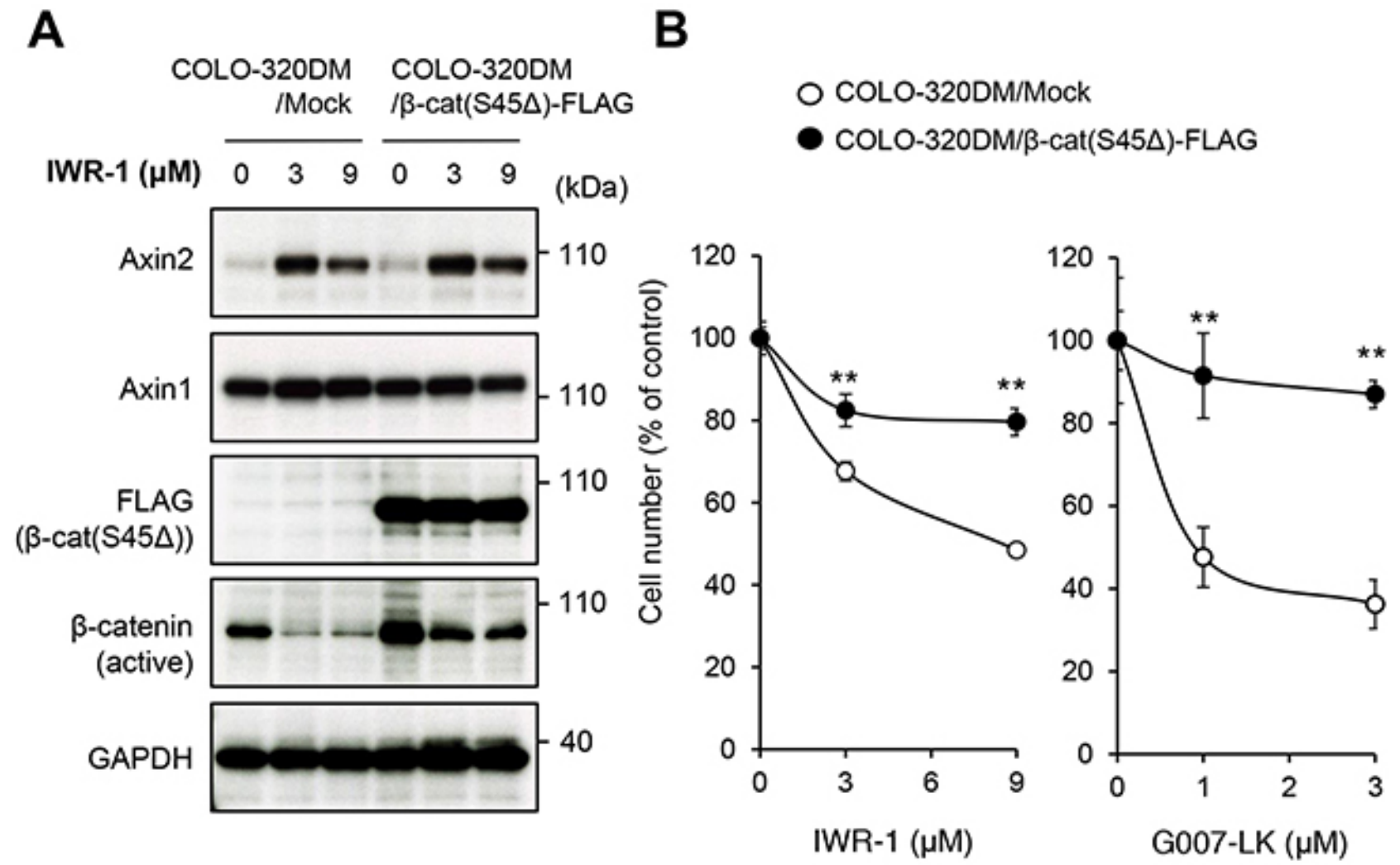

Figure 1: Tankyrase inhibitors suppress colorectal cancer COLO-320DM cell proliferation through inhibition of the $\boldsymbol{\beta}$-catenin pathway. (A) Expression of constitutively active $\beta$-catenin in COLO-320DM cells. Cells were transfected with the plasmid vector expressing active $\beta$-catenin (Ser45 $\Delta$ ) with a FLAG epitope tag or control vector (Mock) as described in the Materials and Methods. At $24 \mathrm{~h}$ after transfection, cells were left untreated or treated with IWR-1 for $16 \mathrm{~h}$. Protein levels of the exogenously expressed constitutively active $\beta$-catenin (FLAG), active $\beta$-catenin which was dephosphorylated on Ser37 or Thr41 (endogenous and exogenous) and Axin1 and 2 were evaluated by western blot analysis. (B) Effect of constitutively active $\beta$-catenin expression on tankyrase inhibitor-induced growth inhibition of COLO-320DM cells. COLO-320DM cells transfected with active $\beta$-catenin (Ser45 $\Delta$ ) or control vector (Mock) were treated with tankyrase inhibitors, IWR-1 or G007-LK, for $120 \mathrm{~h}$. Cell numbers were evaluated as described in the Materials and Methods. Error bars represent standard deviation (SD) of three independent experiments. Statistical significance was evaluated by Tukey-Kramer test $(*: P<0.05 ; * *: P<0.01)$. 
resistant cells and were still effective in suppressing tankyrase PARP activity. We further sequenced two tankyrase isozymes, tankyrase-1 and tankyrase-2, in 320IWR cells, and no acquired mutation was found in these genes (data not shown). Consistent with these results, IWR-1 and G007-LK caused accumulation of Axin2 and down-regulation of active $\beta$-catenin in 320-IWR cells as well as in the parental cells (Figure 3A and 3B). In 320-IWR cells, we observed marginal reduction in Axin 2 protein accumulation and $\beta$-catenin decrease after tankyrase inhibitor treatment, which could lead to slightly reduced pathway inhibition as a cause of resistance to tankyrase inhibitors. Overall, these data indicate that the
tankyrase-Axin2- $\beta$-catenin axis in 320-IWR cells was still sensitive to tankyrase inhibitors.

We next examined the subcellular localization of $\beta$-catenin. As shown in Figure $4 \mathrm{~A}$, the active $\beta$-catenin protein was mainly localized in the nuclei of COLO320DM cells. Meanwhile, in 320-IWR cells, it was diffusely distributed in both the cytoplasm and the nucleus. Given that the total active $\beta$-catenin levels were similar between the two cell lines (Figure 3A and 3B), these results indicate that nuclear active $\beta$-catenin levels were decreased in 320-IWR cells.

Consistent with these observations, the expression of $\mathrm{Wnt} / \beta$-catenin-TCF/LEF pathway genes, $A P C D D 1$,
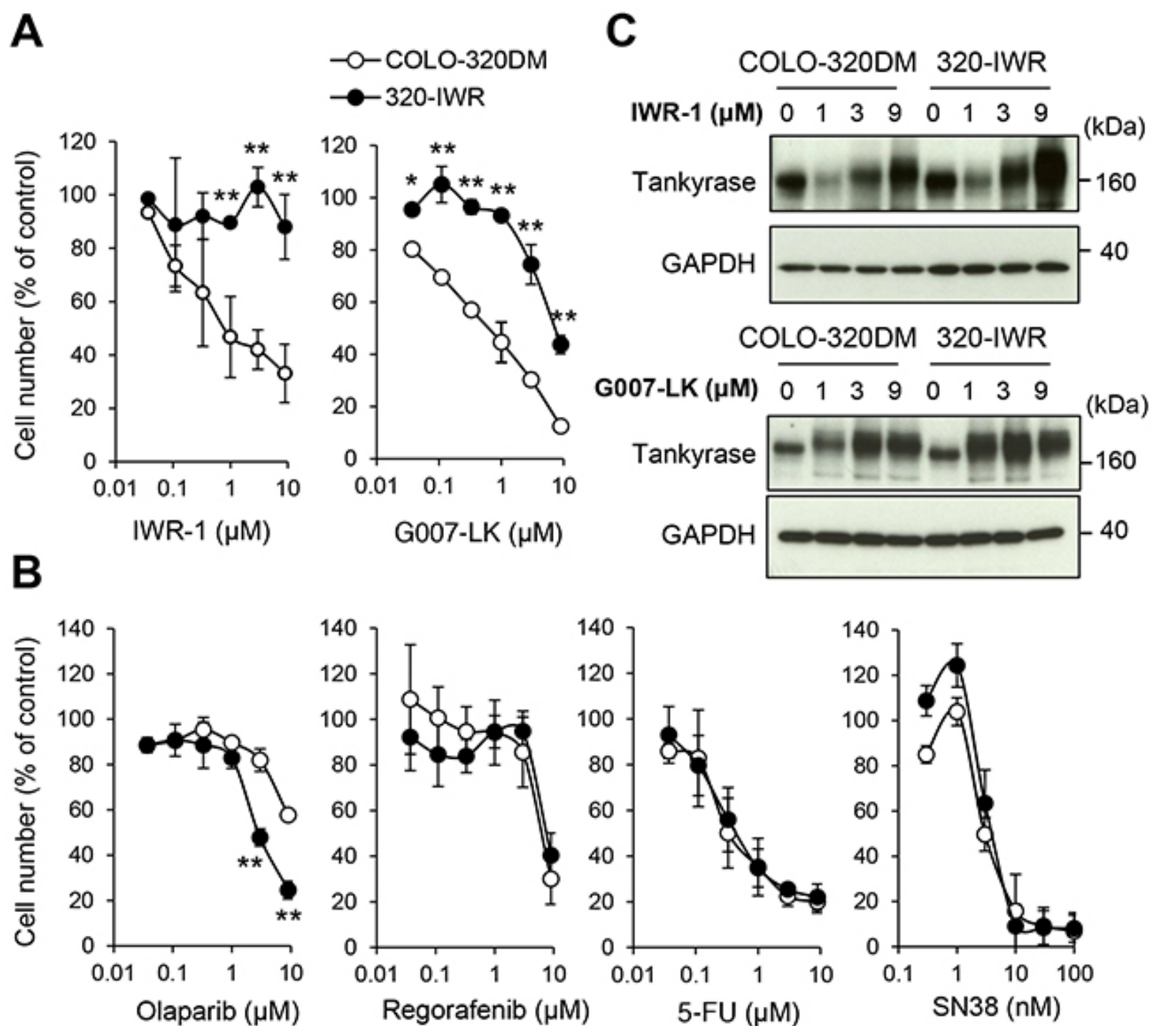

Figure 2: Establishment of 320-IWR, a tankyrase inhibitor-resistant sub-cell line of COLO-320DM cells. (A, B) Selective resistance of 320-IWR cells to tankyrase inhibitors. COLO-320DM and 320-IWR cells were treated with IWR-1 or G007-LK (A) or with olaparib, regorafenib, 5-fluorouracil (5-FU), or SN38, the active metabolite of irinotecan (B) for $120 \mathrm{~h}$. Cell numbers were evaluated as in Materials and Methods. Error bars represent standard deviation (SD) of three independent experiments. Statistical significance was evaluated by Tukey-Kramer test (*: $P<0.05 ; * *: P<0.01)$. (C) Effect of tankyrase inhibitors on tankyrase protein levels in COLO-320DM and 320-IWR cells. Cells were treated with IWR-1 or G007-LK at the indicated concentrations for 16 h. Protein levels of tankyrase and GAPDH as a loading control were evaluated by western blot analysis. 
AXIN2, NKD1, MYC, LEF1, and JAG1 [12, 17] was strongly repressed in 320-IWR cells even in the absence of tankyrase inhibitors (Figure 4B, Supplementary Figure 4A). These genes included $M Y C$, an essential factor in $\mathrm{Wnt} / \beta$-catenin-dependent intestinal tumorigenesis [18]. TCF-dependent transcription activity was also decreased significantly in 320-IWR cells (Supplementary Figure 4B). On the other hand, some $\beta$-catenin target genes (LGR5 and BIRC5) were not down-regulated in 320-IWR cells (Supplementary Figure 4A), and the decrease of TCF promoter activity in 320-IWR cells was not so drastic as transcriptional repression of $\beta$-catenin target genes (Supplementary Figure 4B). These observations suggest that the transcriptional repression of $\beta$-catenin target genes in 320-IWR cells would not only be caused by the decrease in the nuclear $\beta$-catenin levels and transcriptional activity, but also by other factors such as promoter methylation of the genes.

To confirm the role of $\beta$-catenin pathway in 320IWR cells further, we knocked down $\beta$-catenin by siRNA (Supplementary Figure 5A). 320-IWR cells were significantly more resistant to $\beta$-catenin repression than COLO-320DM cells (Supplementary Figure 5B). However, 320-IWR cells were more sensitive to $\beta$-catenin knockdown than to the tankyrase inhibitor-induced downregulation of active $\beta$-catenin (Figures $2 \mathrm{~A}$ and 3 ). This discrepancy would be due to the differential action of tankyrase inhibitors and $\beta$-catenin knockdown: tankyrase inhibitor treatment repressed active $\beta$-catenin expression but not markedly total $\beta$-catenin level, whereas $\beta$-catenin knockdown repressed both the active and total $\beta$-catenin levels clearly (Supplementary Figure 5A).

Collectively, these data indicate that $320-$ IWR cells retained the ability to proliferate despite the repressed $\mathrm{Wnt} / \beta$-catenin signaling. Our observations suggest that the resistant cells could be less addicted to the Wnt/ $\beta$-catenin signaling but depend on alternative signaling pathways for their proliferation.

\section{Activation of the mTOR signaling pathway in 320-IWR cells}

We next performed a genome-wide transcriptome analysis. We extracted genes that were up- or downregulated in 320-IWR cells: genes up- or down-regulated more than 5-fold in 320-IWR cells are shown in Supplementary Table 2. Subsequent gene ontology (GO) analysis revealed that development- or differentiationrelated genes were differentially expressed between 320 IWR and the parental COLO-320DM cells (Table 1). Of note, the $\mathrm{GO}$ analysis also revealed altered expression of genes related to 'catenin import into nucleus', which could be responsible for the altered subcellular localization of active $\beta$-catenin protein in 320-IWR cells (Figure 4A). As for the genes involved in drug detoxification or drug transport, we did not observe any increases in gene expression in 320-IWR cells (Supplementary Figure 6), excluding the possibility that $320-$ IWR cells acquired an enhanced ability to inactivate or efflux the tankyrase inhibitors.
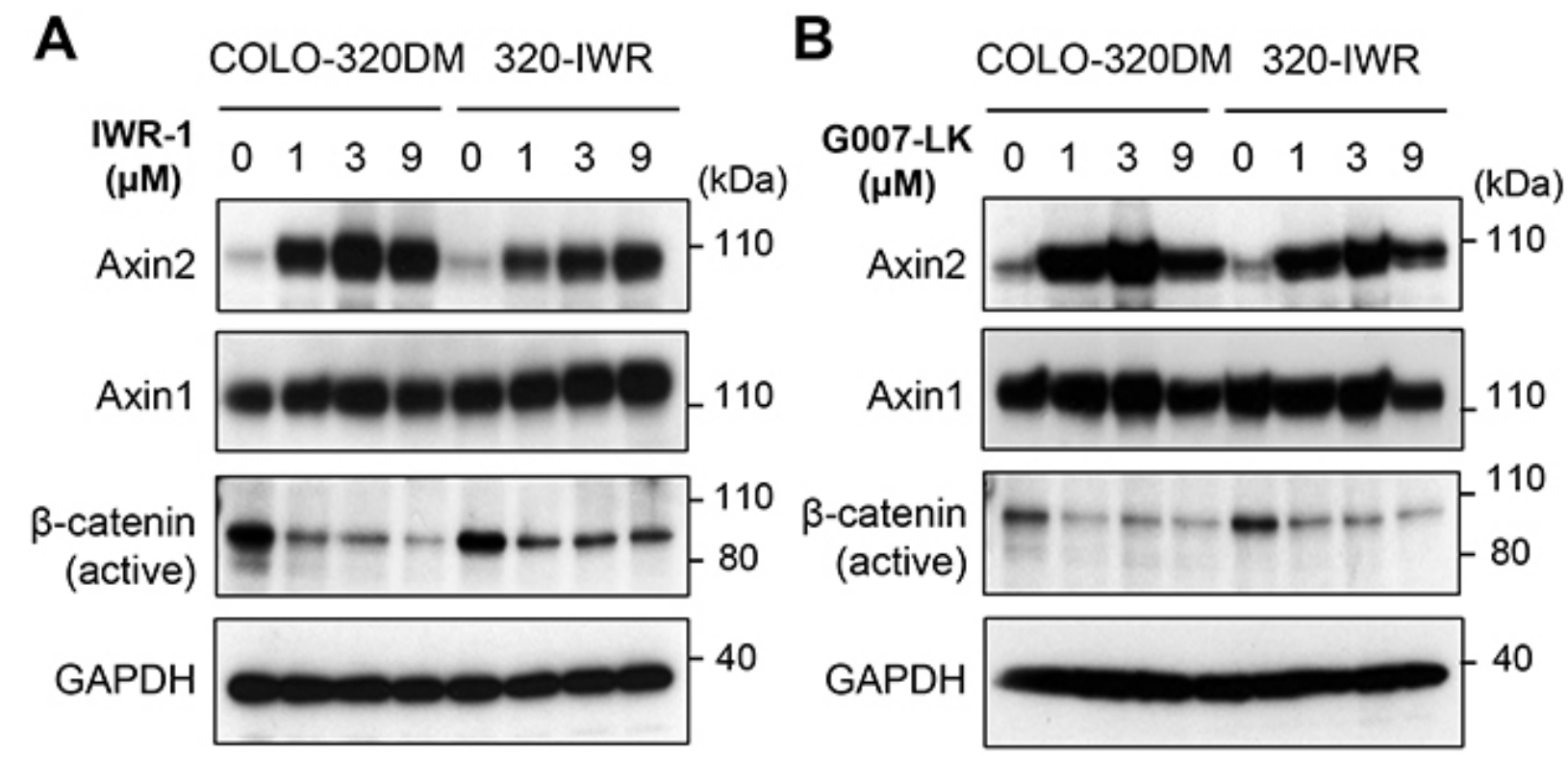

Figure 3: Alteration of canonical Wnt/ $\beta$-catenin signaling in 320-IWR cells. (A, B) Effect of tankyrase inhibitors on protein levels of Wnt/ $\beta$-catenin pathway regulators in COLO-320DM and 320-IWR cells. Cells were treated with IWR-1 and G007-LK at the indicated concentrations for $16 \mathrm{~h}$. Protein levels of Axin1, 2, active $\beta$-catenin (dephosphorylated on Ser37 or Thr41) and GAPDH as a loading control were evaluated by western blot analysis. 
Table 1: Gene Ontology (GO) analysis on the genes selectively expressed in 320-IWR cells

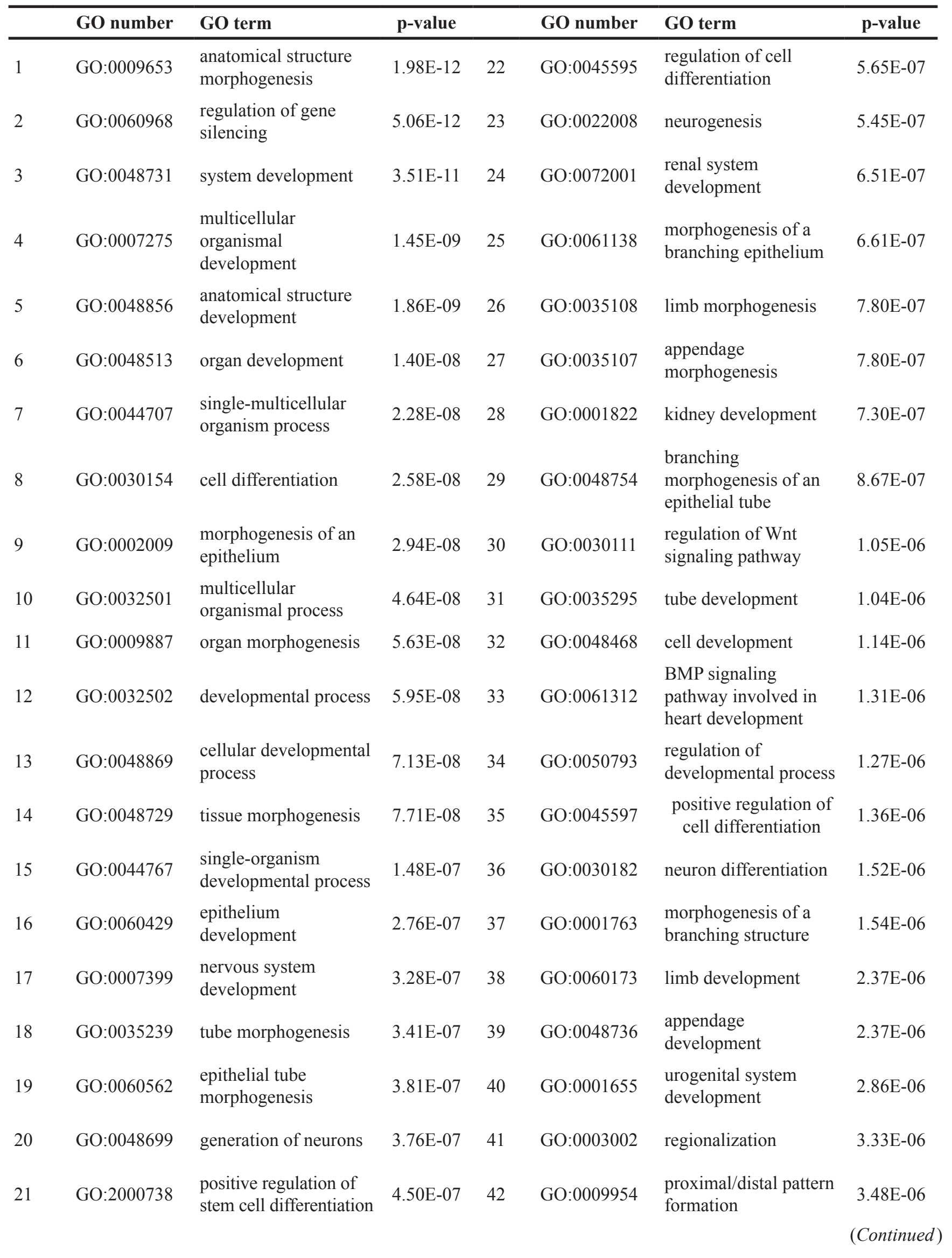




\begin{tabular}{|c|c|c|c|c|c|c|c|}
\hline & GO number & GO term & p-value & & GO number & GO term & p-value \\
\hline 43 & GO:2000736 & $\begin{array}{l}\text { regulation of stem cell } \\
\text { differentiation }\end{array}$ & $3.60 \mathrm{E}-06$ & 57 & GO:0051094 & $\begin{array}{l}\text { positive regulation of } \\
\text { developmental process }\end{array}$ & $9.35 \mathrm{E}-06$ \\
\hline 44 & GO:0048598 & $\begin{array}{l}\text { embryonic } \\
\text { morphogenesis }\end{array}$ & 4.20E-06 & 58 & GO:0072006 & nephron development & $1.13 \mathrm{E}-05$ \\
\hline 45 & GO:0030326 & $\begin{array}{l}\text { embryonic limb } \\
\text { morphogenesis }\end{array}$ & $5.66 \mathrm{E}-06$ & 59 & GO:0002062 & $\begin{array}{l}\text { chondrocyte } \\
\text { differentiation }\end{array}$ & $1.14 \mathrm{E}-05$ \\
\hline 46 & GO:0035113 & $\begin{array}{l}\text { embryonic appendage } \\
\text { morphogenesis }\end{array}$ & $5.66 \mathrm{E}-06$ & 60 & GO:0035412 & $\begin{array}{l}\text { regulation of catenin } \\
\text { import into nucleus }\end{array}$ & $1.29 \mathrm{E}-05$ \\
\hline 47 & GO:0022603 & $\begin{array}{l}\text { regulation of } \\
\text { anatomical structure } \\
\text { morphogenesis }\end{array}$ & $6.13 \mathrm{E}-06$ & 61 & GO:0090092 & $\begin{array}{l}\text { regulation of } \\
\text { transmembrane } \\
\text { receptor protein Ser/ } \\
\text { Thr kinase signaling } \\
\text { pathway }\end{array}$ & $1.39 \mathrm{E}-05$ \\
\hline 48 & GO:0060828 & $\begin{array}{l}\text { regulation of canonical } \\
\text { Wnt signaling pathway }\end{array}$ & $7.02 \mathrm{E}-06$ & 62 & GO:0003307 & $\begin{array}{l}\text { regulation of Wnt } \\
\text { signaling pathway } \\
\text { involved in heart } \\
\text { development }\end{array}$ & $1.43 \mathrm{E}-05$ \\
\hline 49 & GO:0003129 & heart induction & 8.79E-06 & 63 & GO:0000904 & $\begin{array}{l}\text { cell morphogenesis } \\
\text { involved in } \\
\text { differentiation }\end{array}$ & $1.46 \mathrm{E}-05$ \\
\hline 50 & GO:0003130 & $\begin{array}{l}\text { BMP signaling } \\
\text { pathway involved in } \\
\text { heart induction }\end{array}$ & 8.79E-06 & 64 & GO:0010717 & $\begin{array}{l}\text { regulation of epithelial } \\
\text { to mesenchymal } \\
\text { transition }\end{array}$ & $1.74 \mathrm{E}-05$ \\
\hline 51 & GO:0003133 & $\begin{array}{l}\text { endodermal- } \\
\text { mesodermal cell } \\
\text { signaling }\end{array}$ & 8.79E-06 & 65 & GO:0090090 & $\begin{array}{l}\text { negative regulation } \\
\text { of canonical Wnt } \\
\text { signaling pathway }\end{array}$ & $1.89 \mathrm{E}-05$ \\
\hline 52 & GO:0003134 & $\begin{array}{l}\text { endodermal- } \\
\text { mesodermal cell } \\
\text { signaling involved in } \\
\text { heart induction }\end{array}$ & 8.79E-06 & 66 & GO:0051239 & $\begin{array}{l}\text { regulation of } \\
\text { multicellular } \\
\text { organismal process }\end{array}$ & $2.23 \mathrm{E}-05$ \\
\hline 53 & GO:2000026 & $\begin{array}{l}\text { regulation of } \\
\text { multicellular } \\
\text { organismal } \\
\text { development }\end{array}$ & $8.03 \mathrm{E}-06$ & 67 & GO:0009611 & response to wounding & $2.30 \mathrm{E}-05$ \\
\hline 54 & GO:0090081 & $\begin{array}{l}\text { regulation of heart } \\
\text { induction by regulation } \\
\text { of canonical Wnt } \\
\text { signaling pathway }\end{array}$ & 8.79E-06 & 68 & GO:0051093 & $\begin{array}{l}\text { negative regulation of } \\
\text { developmental process }\end{array}$ & $2.39 \mathrm{E}-05$ \\
\hline 55 & GO:1901213 & $\begin{array}{l}\text { regulation of } \\
\text { transcription from } \\
\text { RNA pol II promoter } \\
\text { involved in heart } \\
\text { development }\end{array}$ & 9.09E-06 & 69 & GO:0035413 & $\begin{array}{l}\text { positive regulation of } \\
\text { catenin import into } \\
\text { nucleus }\end{array}$ & $2.54 \mathrm{E}-05$ \\
\hline 56 & GO:0072073 & $\begin{array}{l}\text { kidney epithelium } \\
\text { development }\end{array}$ & $9.45 \mathrm{E}-06$ & 70 & GO:0030178 & $\begin{array}{l}\text { negative regulation of } \\
\text { Wnt signaling pathway }\end{array}$ & $2.53 \mathrm{E}-05$ \\
\hline
\end{tabular}

NOTE: cDNA microarray analysis was performed on COLO-320DM and 320-IWR cells using the GeneChip Human Genome U133 Plus 2.0 array (Affymetrix). Gene ontology (GO) analysis was done with the GeneSpring GX software (Agilent Technologies) on the genes that were more than 2-fold up- or down-regulated in 320-IWR cells. 
Gene set enrichment analysis (GSEA) [19] further revealed that the gene signature related to the mTOR pathway was significantly enriched in 320IWR cells (Figure 5A). The mTOR pathway is often activated in various cancers including CRC and plays a critical role in tumor growth [20]. Phosphorylation of p70S6 kinase (p70S6K) and 4E-BP1, the downstream signaling molecules of the mTOR pathway, was clearly elevated in 320-IWR cells, whereas the phosphorylation levels of mTOR itself were similar between 320-IWR and COLO-320DM cells (Figure 5B). Importantly, the mTOR inhibitors temsirolimus and rapamycin suppressed p70S6K phosphorylation (Supplementary Figure 7A) and showed more prominent anti-proliferative effects on
320-IWR cells when compared with the parental cells (Figure 5C). These results indicate that the activated mTOR pathway could serve as a selective proliferation factor in 320-IWR cells. On the other hand, we could not exclude the possibility of additional alteration in other signaling pathway in 320-IWR cells, because the differential sensitivity to the mTOR inhibitors between 320-IWR and the parental cells was not dramatic.

\section{Activation of mTOR pathway causes resistance to tankyrase inhibitors}

To examine the role of mTOR signaling in resistance to tankyrase inhibitors, we co-treated 320-

A
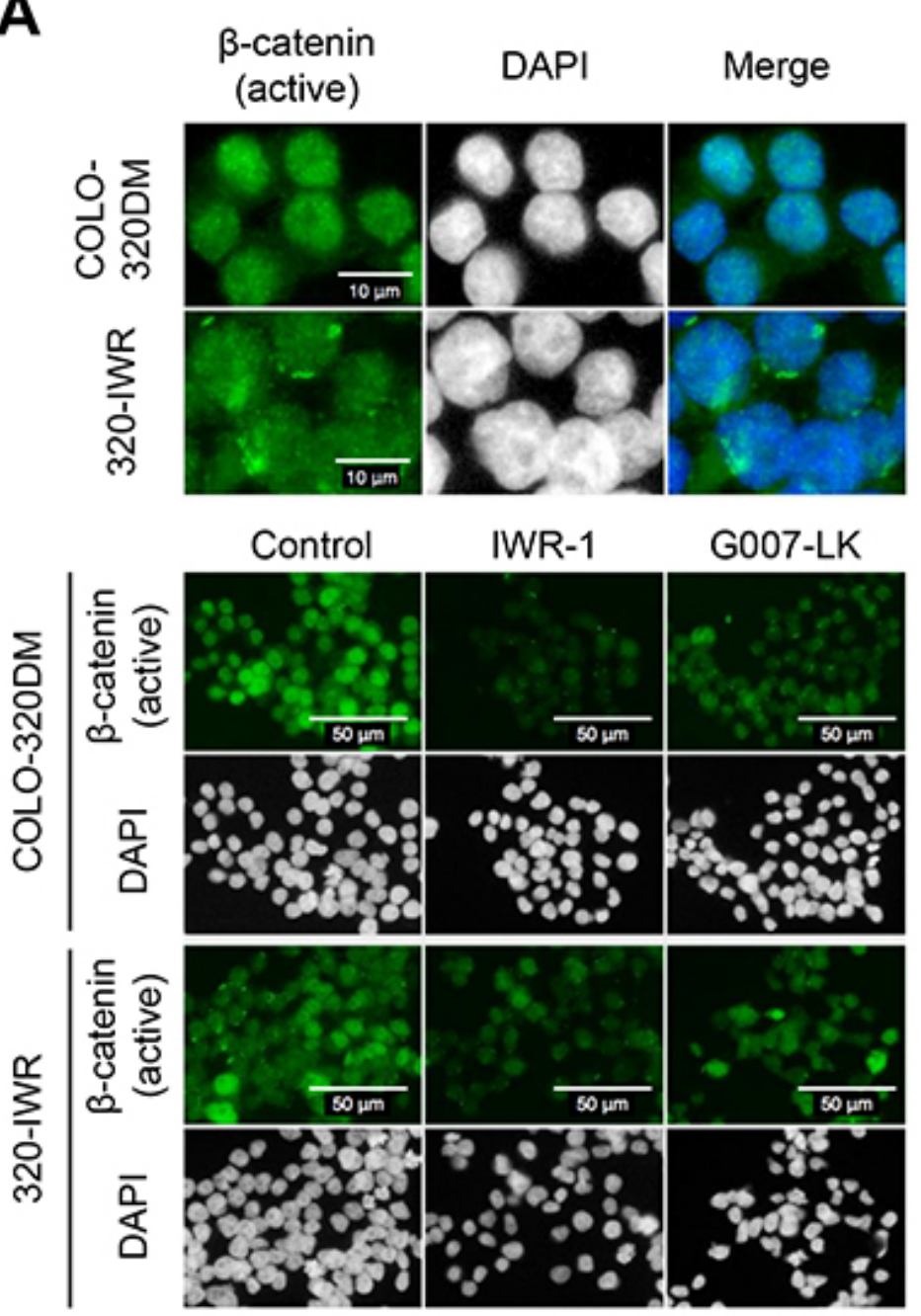

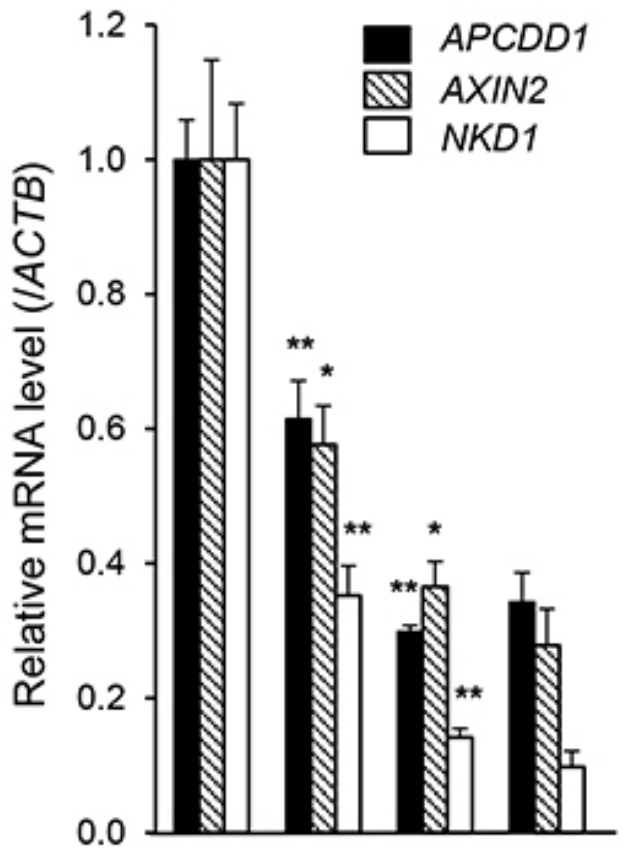

(-) IWR-1 (-) IWR-1

COLO-320DM 320-IWR

Figure 4: Constitutively repressed Wnt/ $\beta$-catenin signaling in 320-IWR cells. (A) Subcellular localization of $\beta$-catenin in COLO-320DM and 320-IWR cells. Cells were left untreated (upper panels and control in lower panels) or treated with $3 \mu \mathrm{M}$ IWR-1 or $3 \mu \mathrm{M}$ G007-LK for $16 \mathrm{~h}$ (lower panels). Cells were subjected to immunofluorescence staining with anti-non-phospho- $\beta$-catenin (green). DAPI staining of nuclear DNA is shown in white. (B) Expression of genes downstream of the Wnt/ $\beta$-catenin pathway in COLO-320DM and 320-IWR cells. Cells were left untreated (-) or treated with $3 \mu \mathrm{M}$ IWR-1 for $16 \mathrm{~h}$. Total RNA was prepared and the expression levels of the Wnt/ $\beta$-catenin pathway genes were analyzed using RT-qPCR. $\beta$-Actin $(A C T B)$ expression was analyzed to normalize the data. Error bars represent standard deviation (SD) of three independent experiments. Statistical significance between untreated and IWR-1-treated COLO-320DM cells or between untreated COLO-320DM and 320-IWR cells was evaluated by Student $t$ test (*: $P<0.05 ; * *: P<0.01)$. 
IWR and parental cells with tankyrase inhibitors and mTOR inhibitor temsirolimus. As shown in Figure 6A, a sub-lethal dose (4 $\mathrm{nM})$ of temsirolimus suppressed p70S6K phosphorylation and dramatically reversed the resistance of 320-IWR cells to IWR-1 (Figure 6B) and G007-LK (Supplementary Figure 7B). Isobologram analysis [21] revealed that the combinational effect of tankyrase inhibitor and mTOR inhibitor in 320-IWR cells was synergistic (Supplementary Figure 7C). To confirm these observations, we further obtained multiple cell clones from 320-IWR cells. In these clones, mTOR
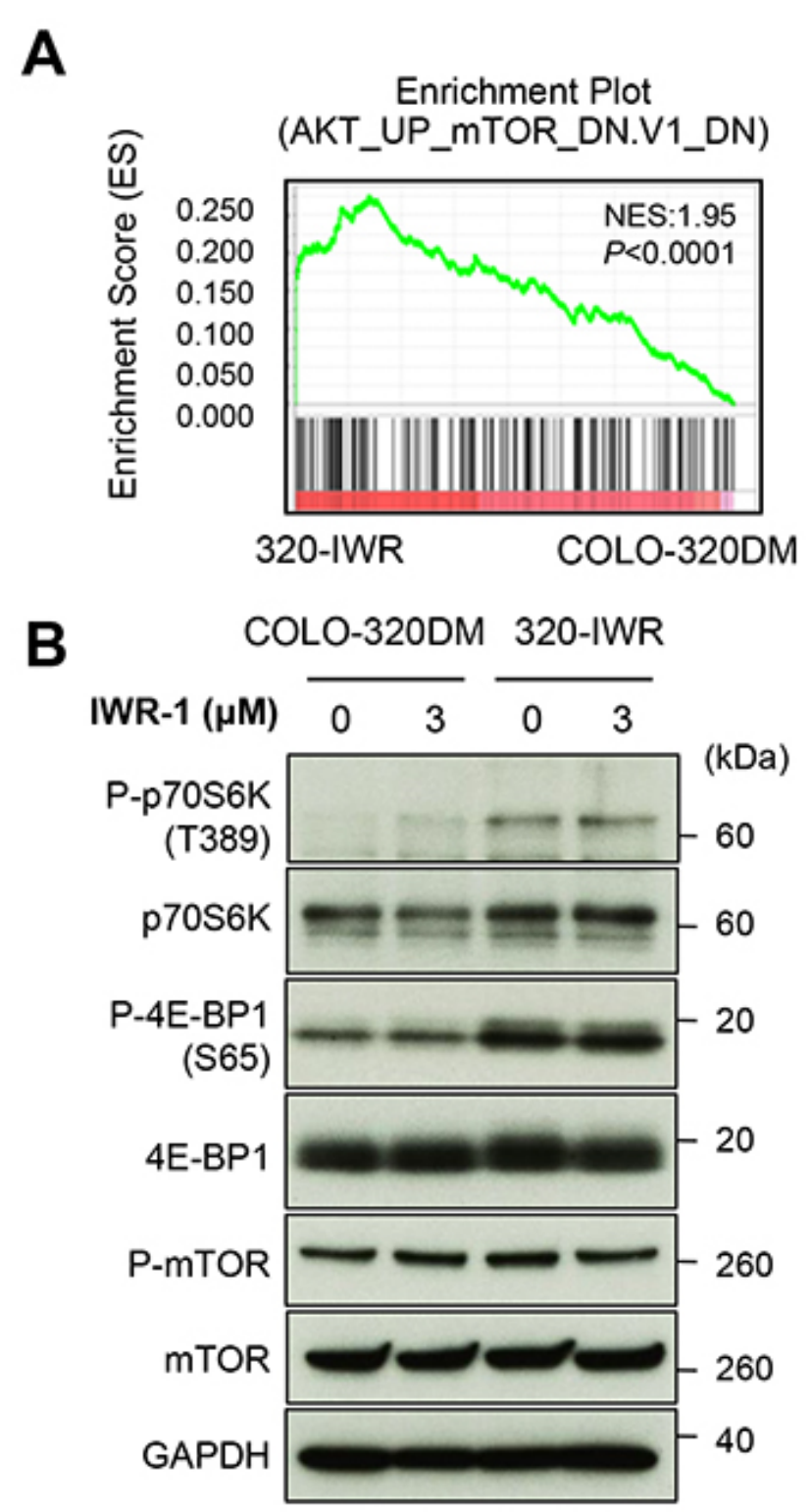

activation, as revealed by $\mathrm{p} 70 \mathrm{~S} 6 \mathrm{~K}$ phosphorylation, was observed and temsirolimus enhanced the growth suppressive effect of IWR-1 (Supplementary Figure 8). At the same time, we also obtained a clone with less mTOR activation (\#3) in which temsirolimus was less effective. These observations suggest additional, mTOR-independent mechanisms of resistance to tankyrase inhibitors in the clone.

The mTOR pathway is frequently activated in CRC cells [20]. To examine whether mTOR signaling could also be involved in intrinsic resistance of CRC cells to
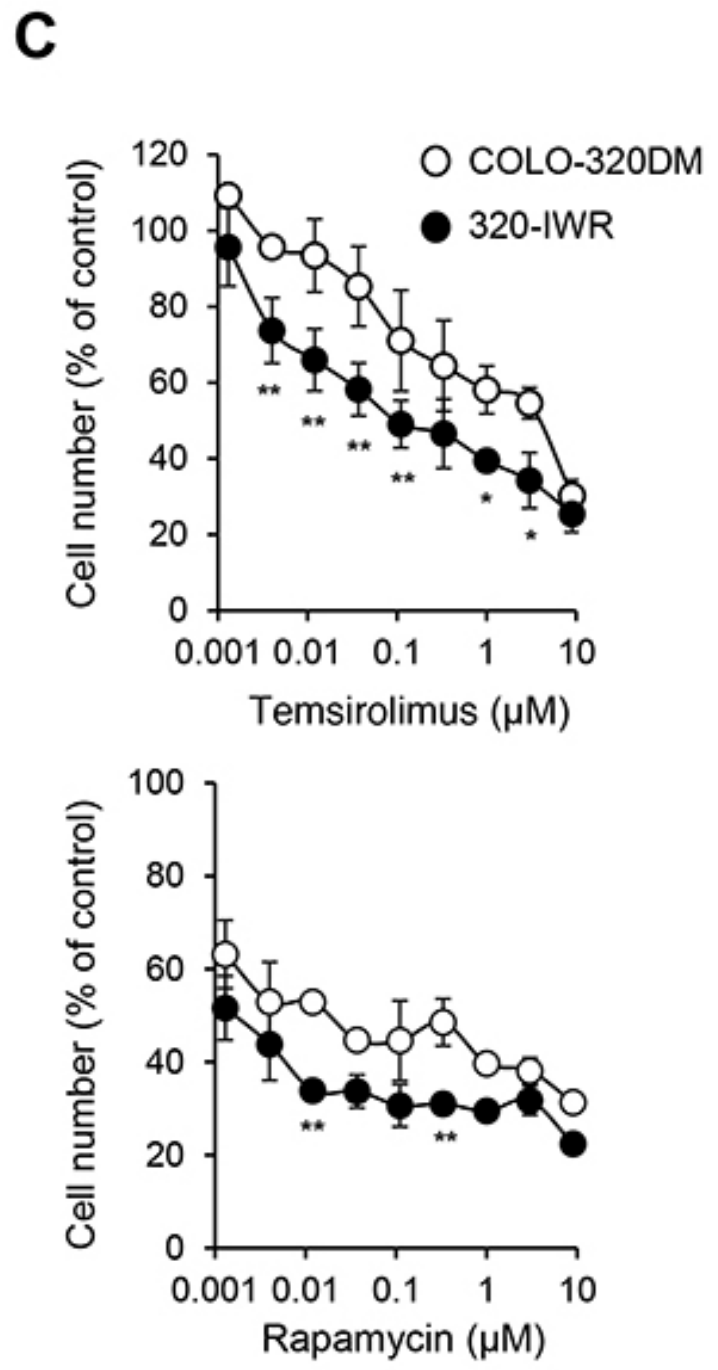

Figure 5: Activation of mTOR signaling pathway in tankyrase inhibitor-resistant 320-IWR cells. (A) Representative result of the Gene Set Enrichment Analysis (GSEA) showing enrichment of the AKT-mTOR pathway-related gene signature in 320-IWR cells. (B) Elevated phosphorylation of mTOR pathway regulators in 320-IWR cells. Cells were left untreated or treated with $3 \mu \mathrm{M}$ IWR-1 for $16 \mathrm{~h}$. Protein levels and phosphorylation status of mTOR pathway regulators were evaluated by western blot analysis. (C) Preferential sensitivity of 320-IWR cells to mTOR inhibitors. COLO-320DM and 320-IWR cells were treated with mTOR inhibitors, temsirolimus or rapamycin, for $120 \mathrm{~h}$. Cell numbers were evaluated as in the Materials and Methods. Error bars represent standard deviation (SD) of three independent experiments. Statistical significance was evaluated by Tukey-Kramer test (*: $P<0.05$; $\left.{ }^{*}: P<0.01\right)$. 
tankyrase inhibitors, we analyzed the mTOR pathway in CRC cell lines. Among the cell lines, we observed phosphorylated p70S6K and 4E-BP1 in CoCM-1 and WiDr cells (Figure 6C). Importantly, temsirolimus enhanced IWR-1-induced growth suppression in these cells (Figure 6D). Isobologram analysis confirmed that the combinational effect of tankyrase inhibitor and mTOR inhibitor in these cells was synergistic (Supplementary Figure 7C). We also tested the combinational effect of tankyrase/mTOR inhibition in two additional CRC cell lines, HCC2998 and DLD-1, which have KRAS mutations and more common APC mutations with two 20-AAR (20-amino acid repeat) motifs. Temsirolimus inhibited the growth of DLD-1 but not HCC2998, and gave no synergistic effect with IWR-1 in these cells (Supplementary Figure 7D). Collectively, these observations indicate that the mTOR pathway is a critical resistant factor to tankyrase inhibitors in a subset of CRC cells.

\section{DISCUSSION}

In this study, we established a tankyrase inhibitorresistant cell line, 320-IWR. 320-IWR cells were resistant to multiple tankyrase inhibitors with different structures, whereas they did not show cross-resistance to a PARP$1 / 2$ inhibitor. These data indicate that the cells were specifically resistant to tankyrase inhibitors but not widely to PARP inhibition. Tankyrase inhibitors are classified into two types: one type targeting the nicotinamide subsite of the tankyrase protein, which is conserved in various PARPs, and the other targeting a unique adenosine subsite that is more potent and specific to tankyrase [22]. Since IWR-1 and G007-LK belong to the latter class of tankyrase inhibitors, it is reasonable that the resistant mechanisms are also specific to tankyrase inhibitors. Acquired resistance to molecularly -targeted drugs is often caused by mutations around the drug-binding sites in target molecules [23]. However, no acquired mutation
A

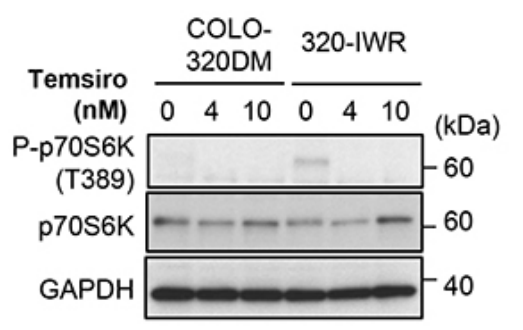

C

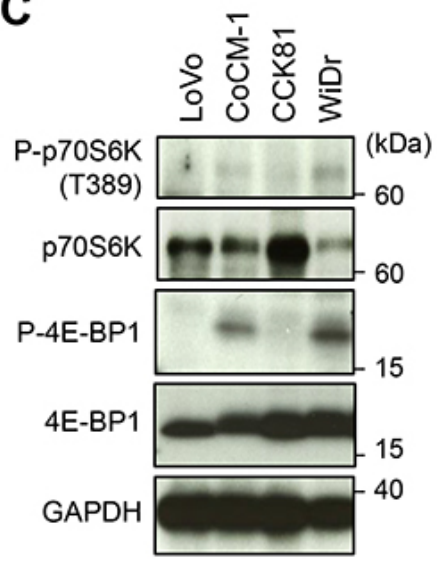

B

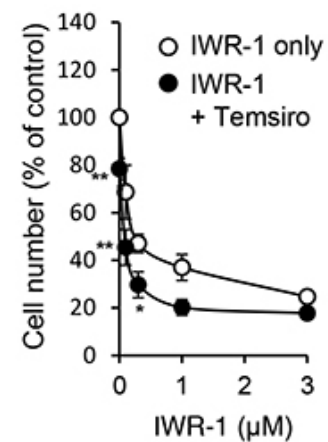

D

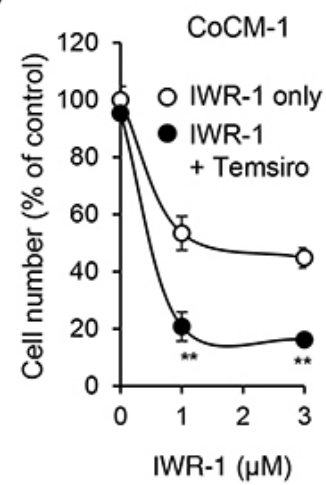

320-IWR
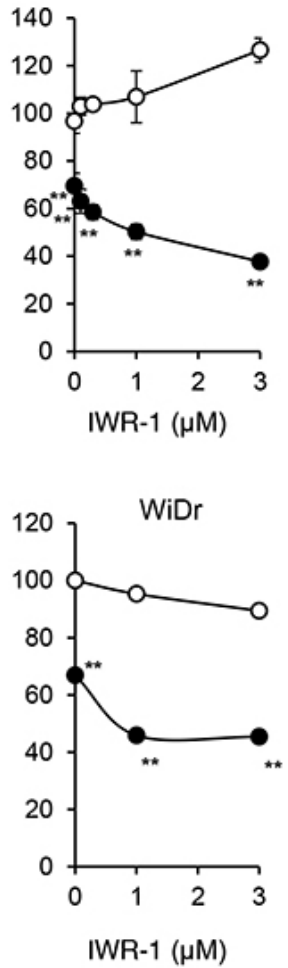

Figure 6: mTOR pathway activation confers resistance to tankyrase inhibition in 320-IWR cells. (A) Inhibition of p70S6 kinase (p70S6K) phosphorylation by an mTOR inhibitor. Cells were treated with temsirolimus (Temsiro) at the indicated concentrations for $2 \mathrm{~h}$. Protein levels and phosphorylation status of p70S6K were evaluated by western blot analysis. (B) Reversal of tankyrase inhibitor resistance in 320-IWR cells by temsirolimus. COLO-320DM and 320-IWR cells were treated with IWR-1 and $4 \mathrm{nM}$ temsirolimus (Temsiro) together at the indicated concentrations for $120 \mathrm{~h}$. Cell numbers were calculated as in the Materials and Methods. Error bars represent standard deviation (SD) of three independent experiments. Statistical significance was evaluated by Tukey-Kramer test $(*: P<0.05$; $* *: P<0.01)$. (C) Expression and phosphorylation of p70S6 kinase (p70S6K) and 4E-BP1 in CRC cells. Protein levels and phosphorylation of p70S6K were evaluated by western blot analysis. (D) Potentiation of the anti-proliferative effect of IWR-1 by temsirolimus. Cells were treated with IWR-1 at the indicated concentrations and $10 \mathrm{nM}$ temsirolimus (Temsiro) together for $120 \mathrm{~h}$. Cell numbers were calculated. Error bars represent standard deviation (SD) of three independent experiments. Statistical significance was evaluated by Tukey-Kramer test $(* *: P<0.01)$. 
was found in tankyrase genes in 320-IWR cells, and inhibition of tankyrase PARP activity by the inhibitors was observed in 320-IWR cells in a similar manner to that in the parental COLO-320DM cells, as revealed by accumulation of Axin2 and tankyrase itself, the substrate proteins of tankyrase (Figures $2 \mathrm{C}$ and $3 \mathrm{~A}$ ).

320-IWR cells showed collateral sensitivity to a PARP-1/2 inhibitor, olaparib (Figure 2B). These data could provide an important clue to a therapeutic approach for recurrent tumors after treatment with tankyrase inhibitors. PARP-1 and 2 play essentials role in DNA repair, and synthetic lethality is shown between PARP-1/2 inhibition and BRCA $1 / 2$ deficiency, essential factors for DNA homologous recombination [24]. Synthetic lethality between tankyrase inhibition and BRCA deficiency was also reported [25]. These observations suggest that tankyrase could also be involved in a particular DNA repair pathway, and alteration of the pathway after long exposure to a tankyrase inhibitor would affect the sensitivity of 320-IWR cells to olaparib.

Our data have shown the involvement of mTOR signaling in resistance to tankyrase inhibitors. At present, it is still elusive as to how the mTOR pathway is activated in the resistant cells. It was reported that PTEN is a substrate of tankyrase, and PARylation of PTEN by tankyrase promotes PTEN degradation and activation of downstream AKT [26]. However, after tankyrase inhibitor treatment, we did not observe any marked changes in the phosphorylation of AKT (Y. Muramatsu, unpublished observation) and its downstream molecule mTOR (Figure 5B) in 320-IWR and COLO-320DM cells. Moreover, in 320-IWR cells, phosphorylation of p70S6K and 4E-BP1, the downstream mediators of mTOR signaling, were elevated without any change in mTOR phosphorylation (Figure 5B). These data indicate that the phosphorylation of p70S6K and 4E-BP1 may not be caused by activation of the AKT-mTOR axis. In the mTOR pathway, there are two regulator complexes, mTORC1 and mTORC2. p70S6K and 4E-BP1 are regulated by the mTORC1 complex, which consists of mTOR and its regulators such as Raptor [20]. Further analyses are required to determine whether components of the mTORC1 complex could be altered in 320-IWR cells. On the other hand, mTOR activation in 320-IWR might be caused by a more dramatic phenotypic change, since continuous treatment with tankyrase inhibitors could affect the $\mathrm{Wnt} / \beta$-catenin pathway, which is involved in cellular differentiation. Indeed, expression of differentiation-related genes was largely changed between 320-IWR and COLO-320DM cells (Table 1). Particularly, 320-IWR cells overexpressed prominin 1 (CD133) (Supplementary Table 2), a wellknown marker of cancer stem cells [27], and mTOR activation was also reported in cancer stem cells [28]. Additional studies would clarify the relationship of tankyrase inhibitor sensitivity to cancer stemness.
Activation of the mTOR pathway emerged as a mechanism of resistance to $\mathrm{Wnt} / \beta$-catenin pathway inhibition by tankyrase inhibitors. This implies potentially compensatory roles of the two signaling pathways. Indeed, $\beta$-catenin was reported to confer resistance to inhibitors of phosphatidylinositol 3-kinase (PI3K) and AKT, upstream regulators of the mTOR pathway [29]. The mTOR pathway is often activated in CRC cells [21], and therefore mTOR activation could not only be involved in the acquired resistance but also in the intrinsic resistance to tankyrase inhibitors in CRC. We identified mTOR signaling-mediated resistance to tankyrase inhibitors in COLO-320DM cells, which possess short truncated APC lacking all the 20-aa repeats [12] and are devoid of KRAS and PIK3CA mutation. In our recent analysis with CRC patient-derived cells, hemizygous short APC mutations were observed in six out of 16 APC-mutated CRCs [30]. According to the TCGA mutational analysis [31], there is also a subclass of CRCs without any mutations in KRAS or PIK3CA. In our data, mTOR inhibitor enhanced tankyrase inhibitor cytotoxicity in CoCM1 cells with PIK3CA(R1023Q) mutation [32], and in WiDr cells having BRAF(V600E) and PIK3CA(P449T) mutation (Figure 6D) [33]. From these results, mTOR pathway would interfere with the anti-proliferative effect of tankyrase inhibitors in several types of CRC. Nevertheless, further validation studies with more comprehensive setting, including larger number of cell lines and patientderived cells, are needed to evaluate how generalizable the effect would be. Additionally, the combinational effect of tankyrase and mTOR inhibitors should be validated in vivo. Our analyses with 320-IWR-derived clones also suggested mTOR-independent mechanisms of tankyrase inhibitor-resistance. Further studies are required to identify these mechanisms of resistance to tankyrase inhibitors.

\section{MATERIALS AND METHODS}

\section{Cell lines and chemical compounds}

Human colorectal cancer COLO-320DM cells were obtained from the American Type Cell Collection (ATCC). Human colorectal cancer LoVo, CoCM-1, CCK81 and WiDr cells were obtained from the JCRB cell bank (Osaka, Japan). Human colorectal cancer HCC-2998 and DLD-1 cells were obtained as described previously [30]. These cell lines were authenticated by short tandem repeat (STR) analysis (BEX, Tokyo, Japan). STR analysis was also performed in 320-IWR cells and we confirmed that the cells were derived from COLO-320DM cells. Cell culture conditions for each cell line are described in the Supplementary Materials and Methods. Information on chemical compounds used in this study (tankyrase inhibitors, mTOR inhibitors and other agents) is detailed in Supplementary Materials and Methods. 


\section{Vector construction and transfection}

Full-length cDNA for constitutively active human $\beta$-catenin with a deleted mutation at Ser45 [14] was amplified by PCR using cDNA extracted from human CRC HCT116 cells as a template. The cDNA was cloned into a pLPCX vector (Takara) with a FLAG epitope tag at the carboxyl-terminus to generate pLPCX- $\beta$-catenin (Ser45 $\Delta$ )-FLAG. COLO-320DM cells were transiently transfected with the pLPCX- $\beta$-catenin (Ser45 $\Delta$ )FLAG or pLPCX control vectors by lipofection with Lipofectamine 2000 reagent (Thermo Fisher Scientific) or by electroporation using the Neon transfection system (Thermo Fisher Scientific) according to manufacturer's instructions.

\section{Cell proliferation assay}

Cell proliferation was evaluated using thiazolyl blue tetrazolium bromide (MTT) (Sigma). Cells were seeded in 96-well microplates and were treated with drugs for 5 days. The detailed procedure is described in Supplementary Materials and Methods.

\section{Western blot analysis}

Cells were lysed in whole cell extract (WCE) lysis buffer $[150 \mathrm{mM} \mathrm{NaCl}, 1.0 \%$ Nonidet P-40 (NP-40), $50 \mathrm{mM}$ Tris- $\mathrm{HCl}, \mathrm{pH} 8.0$ ] supplemented with $1 \times$ protease inhibitor cocktail (Nacalai) and PhosSTOP phosphatase inhibitor cocktail (Roche). Western blot analysis was performed as described previously [34]. Antibodies used in this study are described in Supplementary Materials and Methods.

\section{Immunofluorescence staining}

Cells were fixed with $2 \%$ paraformaldehyde in phosphate-buffered saline (PBS) and were permeabilized with $0.5 \%$ NP-40 in PBS. The fixed cells were blocked in PBS containing $1 \%$ bovine serum albumin (BSA) and reacted with the rabbit anti-non-phospho (active) $\beta$-catenin (S33/S37/T41) antibody (Cell Signaling Technology). This primary antibody was detected using the Alexa 488-conjugated anti-rabbit immunoglobulin (IgG). DNA was stained with $0.2 \mu \mathrm{g} / \mathrm{mL}$ 4',6-diamidino-2-phenylindole (DAPI).

\section{Reverse transcription-quantitative PCR (RT- qPCR)}

Total RNA was extracted using the RNeasy Mini kit (Qiagen). cDNA was synthesized using SuperScript III First-Strand Synthesis SuperMix for RT-qPCR (Thermo Fisher Scientific). RT-qPCR was performed using LightCycler 480 Probes Master (Roche) and detected using a LightCycler 96 (Roche). A Universal ProbeLibrary
Human ACTB Gene Assay was used to detect a reference gene to normalize for differences in the amount of RNA in each sample. All probes were purchased from Roche. Primers and probes for RT-qPCR are shown in the Supplementary Table 3.

\section{cDNA microarray analysis and Gene Set Enrichment Analysis (GSEA)}

Total RNA was extracted as described above. cDNA microarray analysis was performed with the RNAs as described previously [26], using the GeneChip Human Genome U133 Plus 2.0 Array (Affymetrix). Normalization of data and Gene Ontology (GO) analysis were performed with the GeneSpring GX software (Agilent Technologies). Gene Set Enrichment Analysis (GSEA) (Broad Institute) was performed on the website (http://software.broadinstitute. org/gsea/index.jsp).

The gene expression data have been deposited in Gene Expression Omnibus (GEO) and are accessible through the accession number GSE86061. The data were released on November 1, 2016.

\section{ACKNOWLEDGMENTS}

The authors thank Dr. Fumiyuki Shirai (RIKEN) for kindly providing us with G007-LK. The authors also thank Ms. Naomi Kawata for technical assistance, Drs. Masaaki Matsuura and Masaru Ushijima for helpful comments on statistical analysis and members of the Seimiya laboratory for helpful discussion. We are grateful to Dr. Kunitada Shimotohno (National Center for Global Health and Medicine) for providing us with pTcf7mt-luc and pTcfwtluc reporter vectors. This study was supported by a Grantin-Aid for Scientific Research (B) from the Ministry of Education, Culture, Sports, Science and Technology of Japan (16H04716 to HS) and the grant from Japan Agency for Medical Research and Development (AMED, $16 \mathrm{~cm} 0106102 \mathrm{~h} 0001$ to HS).

\section{CONFLICTS OF INTEREST}

The authors declare no conflicts of interest.

\section{REFERENCES}

1. Nielsen DL, Palshof JA, Larsen FO, Jensen BV, Pfeiffer P. A systematic review of salvage therapy to patients with metastatic colorectal cancer previously treated with fluorouracil, oxaliplatin and irinotecan $+/$ - targeted therapy. Cancer Treat Rev. 2014; 40: 701-715.

2. Smith G, Carey FA, Beattie J, Wilkie MJ, Lightfoot TJ, Coxhead J, Garner RC, Steele RJ, Wolf CR. Mutations in APC, Kirsten-ras, and p53--alternative genetic pathways to colorectal cancer. Proc Natl Acad Sci U S A. 2002; 99 : 9433-9938. 
3. Fodde R, Smits R, Clevers H. APC, signal transduction and genetic instability in colorectal cancer. Nat Rev Cancer. 2001; 1: 55-67.

4. Li VS, Ng SS, Boersema PJ, Low TY, Karthaus WR, Gerlach JP, Mohammed S, Heck AJ, Maurice MM, Mahmoudi T, Clevers H. Wnt signaling through inhibition of $\beta$-catenin degradation in an intact Axin 1 complex. Cell. 2012; 149: 1245-1256.

5. Dow LE, O'Rourke KP, Simon J, Tschaharganeh DF, van Es JH, Clevers H, Lowe SW. Apc restoration promotes cellular differentiation and reestablishes crypt homeostasis in colorectal cancer. Cell. 2015; 161: 1539-1552.

6. Smith S, Giriat I, Schmitt A, de Lange T. Tankyrase, a poly(ADP-ribose) polymerase at human telomeres. Science 1998; 282: 1484-1487.

7. Seimiya H. The telomeric PARP, tankyrases, as targets for cancer therapy. Br J Cancer. 2006; 94: 341-345.

8. Huang SM, Mishina YM, Liu S, Cheung A, Stegmeier F, Michaud GA, Charlat O, Wiellette E, Zhang Y, Wiessner S, Hild M, Shi X, Wilson CJ, et al. Tankyrase inhibition stabilizes axin and antagonizes Wnt signalling. Nature. 2009; 461: 614-620.

9. Zhang Y, Liu S, Mickanin C, Feng Y, Charlat O, Michaud GA, Schirle M, Shi X, Hild M, Bauer A, Myer VE, Finan PM, Porter JA, et al. RNF146 is a poly(ADP-ribose)directed E3 ligase that regulates axin degradation and Wnt signalling. Nat Cell Biol. 2011; 13: 623-9.

10. Chen B, Dodge ME, Tang W, Lu J, Ma Z, Fan CW, Wei S, Hao W, Kilgore J, Williams NS, Roth MG, Amatruda JF, Chen C, et al. Small molecule-mediated disruption of Wntdependent signaling in tissue regeneration and cancer. Nat Chem Biol. 2009; 5: 100-107.

11. Yashiroda Y, Okamoto R, Hatsugai K, Takemoto Y, Goshima N, Saito T, Hamamoto M, Sugimoto Y, Osada H, Seimiya H, Yoshida M. A novel yeast cell-based screen identifies flavone as a tankyrase inhibitor. Biochem Biophys Res Commun. 2010; 394: 569-573.

12. Lau T, Chan E, Callow M, Waaler J, Boggs J, Blake RA, Magnuson S, Sambrone A, Schutten M, Firestein R, Machon O, Korinek V, Choo E, et al. A novel tankyrase small-molecule inhibitor suppresses APC mutationdriven colorectal tumor growth. Cancer Res. 2013; 73: 3132-3144.

13. Quackenbush KS, Bagby S, Tai WM, Messersmith WA, Schreiber A, Greene J, Kim J, Wang G, Purkey A, Pitts TM, Nguyen A, Gao D, Blatchford P, et al. The novel tankyrase inhibitor (AZ1366) enhances irinotecan activity in tumors that exhibit elevated tankyrase and irinotecan resistance. Oncotarget. 2016; 7: 28273-28285. doi: 10.18632/ oncotarget.8626.

14. Sekine S, Shibata T, Sakamoto M, Hirohashi S. Target disruption of the mutant $\beta$-catenin gene in colon cancer cell line HCT116: preservation of its malignant phenotype. Oncogene. 2002; 21: 5906-5911.
15. Liu C, Li Y, Semenov M, Han C, Baeg GH, Tan Y, Zhang Z, Lin X, He X. Control of beta-catenin phosphorylation/ degradation by a dual-kinase mechanism. Cell. 2002; 108: 837-847.

16. Kaler P, Augenlicht L, Klampfer L. Activating mutations in $\beta$-catenin in colon cancer cells alter their interaction with macrophages; the role of snail. PLoS One. 2012; 7: e45462.

17. Herbst A, Jurinovic V, Krebs S, Thieme SE, Blum H, Göke B, Kolligs FT. Comprehensive analysis of $\beta$-catenin target genes in colorectal carcinoma cell lines with deregulated Wnt/B-catenin signaling. BMC Genomics. 2014; 15: 1471-2164.

18. Sansom OJ, Meniel VS, Muncan V, Phesse TJ, Wilkins JA, Reed KR, Vass JK, Athineos D, Clevers H, Clarke AR. Myc deletion rescues Apc deficiency in the small intestine. Nature. 2007; 446: 676-679.

19. Subramanian A, Tamayo P, Mootha VK, Mukherjee S, Ebert BL, Gillette MA, Paulovich A, Pomeroy SL, Golub TR, Lander ES, Mesirov JP. Gene set enrichment analysis: a knowledge-based approach for interpreting genome-wide expression profiles. Proc Natl Acad Sci U S A. 2005; 102: 15545-15550.

20. Francipane MG, Lagasse E. mTOR pathway in colorectal cancer: an update. Oncotarget. 2014; 5: 49-66. doi: 10.18632/oncotarget.1548.

21. Tallarida RJ. An overview of drug combination analysis with isobolograms. J Pharmacol Exp Ther. 2006; 319: 1-7.

22. Lehtiö L, Chi NW, Krauss S. Tankyrase as drug targets. FEBS J. 2013; 280: 3576-3593.

23. Oxnard GR, Arcila ME, Chmielecki J, Ladanyi M, Miller VA, Pao W. New strategies in overcoming acquired resistance to epidermal growth factor receptor tyrosine kinase inhibitors in lung cancer. Clin Cancer Res. 2011; 17: 5530-5537.

24. Farmer H, McCabe N, Lord CJ, Tutt AN, Johnson DA, Richardson TB, Santarosa M, Dillon KJ, Hickson I, Knights C, Martin NM, Jackson SP, Smith GC, et al. Targeting the DNA repair defect in BRCA mutant cells as a therapeutic strategy. Nature. 2005; 434: 917-921.

25. McCabe N, Cerone MA, Ohishi T, Seimiya H, Lord CJ, Ashworth A. Targeting Tankyrase 1 as a therapeutic strategy for BRCA-associated cancer. Oncogene. 2009; 28 : 1465-1470.

26. Li N, Zhang Y, Han X, Liang K, Wang J, Feng L, Wang W, Songyang Z, Lin C, Yang L, Yu Y, Chen J. Poly-ADP ribosylation of PTEN by tankyrases promotes PTEN degradation and tumor growth. Genes Dev. 2015; 29: 157-170.

27. Kemper K, Grandela C, Medema JP. Molecular identification and targeting of colorectal cancer stem cells. Oncotarget. 2010; 1: 387-395. doi: 10.18632/ oncotarget.101003.

28. Zhou J, Wulfkuhle J, Zhang H, Gu P, Yang Y, Deng J, Margolick JB, Liotta LA, Petricoin E 3rd, Zhang 
Y. Activation of the PTEN/mTOR/STAT3 pathway in breast cancer stem-like cells is required for viability and maintenance. Proc Natl Acad Sci U S A. 2007; 104: 16158-16163.

29. Tenbaum SP1, Ordóñez-Morán P, Puig I, Chicote I, Arqués O, Landolfi S, Fernández Y, Herance JR, Gispert JD, Mendizabal L, Aguilar S, Ramón y Cajal S, Schwartz $\mathrm{S}$ Jr, et al. $\beta$-catenin confers resistance to PI3K and AKT inhibitors and subverts FOXO3a to promote metastasis in colon cancer. Nat Med. 2012; 18: 892-901.

30. Tanaka N, Mashima T, Mizutani A, Sato A, Aoyama A, Gong B, Yoshida H, Muramatsu Y, Nakata K, Matsuura M, Katayama R, Nagayama S, Fujita N, et al. APC mutations as a potential biomarker for sensitivity to tankyrase inhibitors in colorectal cancer. Mol Cancer Ther. 2017; 16: 752-762.

31. Muzny DM, Bainbridge MN, Chang K, Dinh HH, Drummond JA, Fowler G, Kovar CL, Lewis LR, Morgan MB, Newsham IF, Reid JG, Santibanez J, Shinbrot E, et al. Comprehensive molecular characterization of human colon and rectal cancer. Nature. 2012; 487: 330-337.
32. Ebi H, Corcoran RB, Singh A, Chen Z, Song Y, Lifshits E, Ryan DP, Meyerhardt JA, Benes C, Settleman J, Wong KK, Cantley LC, Engelman JA. Receptor tyrosine kinases exert dominant control over PI3K signaling in human KRAS mutant colorectal cancers. J Clin Invest. 2011; 121 : 4311-4321.

33. Ahmed D, Eide PW, Eilertsen IA, Danielsen SA, Eknæs M, Hektoen M, Lind GE, Lothe RA. Epigenetic and genetic features of 24 colon cancer cell lines. Oncogenesis. 2013;2: e71.

34. Mashima T, Soma-Nagae T, Migita T, Kinoshita R, Iwamoto A, Yuasa T, Yonese J, Ishikawa Y, Seimiya H. TRIB1 supports prostate tumorigenesis and tumor-propagating cell survival by regulation of endoplasmic reticulum chaperone expression. Cancer Res. 2014; 74: 4888-4897.

35. Mashima T, Okabe S, Seimiya H. Pharmacological targeting of constitutively active truncated androgen receptor by nigericin and suppression of hormone-refractory prostate cancer cell growth. Mol Pharmacol. 2010; 78:846-854. 